\title{
Climate Crises and
}

\section{Crypto-Colonialism: Conjuring Value on the Blockchain Frontiers of the Global South}

\section{Peter Howson* \\ School of Arts and Humanities, Nottingham Trent University, Nottingham, United Kingdom}

This commentary explores how climate crises are used to justify "crypto-colonialism," whereby blockchain technology is used to extract economic benefits from those suffering the scars of historic colonial expansion in the Global South. These benefits include land, labor, data and other resources needed to facilitate capital interests elsewhere. As with past neoliberal development agendas imposing structural economic reforms, the contemporary crypto-colonial exercises discussed here are driven in pursuit of a common good - to protect the global commons and improve people's lives. The paper explores how investors are drawn to the sustainable development frontiers - the code/spaces where crypto-colonial conjuring manifests. Blockchain is implicated within crypto-colonialism in three ways. Firstly, it plays into ongoing narratives of "green grabbing," where local claims to resources are liquidated for green investments. Secondly, the technology perpetuates North-South trade and investment inequalities, and thirdly, a new power asymmetry is enabled by the technology through data colonialism and surveillance capitalism. In reviewing the spaces where crypto-colonialism manifests, the paper argues that despite being distributed, technoecological fixes are never placeless. How people configure, use, and are impacted by blockchain platforms is geographically contingent.

Keywords: blockchain, crypto-colonialism, cryptocurrencies, green grabbing, climate crises, Global South

\section{INTRODUCTION}

Anthropogenic greenhouse gas emissions present unprecedented, and not evenly distributed, challenges for human development globally. Each year, an average of 24 million people are displaced because of increasingly frequent extreme climatic events. By 2050, 143 million people across the Global South will become climate refugees (Kinstler, 2019). There is also broad consensus that climate change is exacerbating a mass-extinction of biodiversity with no historical equivalence (Bálint et al., 2011). Addressing such crises is becoming a boom industry; a source of substantial economic growth in a variety of sectors (Büscher and Fletcher, 2020). It is also inspiring new technical fixes using blockchain technology. Despite promises of transforming the opaque world of climate finance (Marke, 2018), providing disaster preparedness solutions for local communities in the Global South (Thomason et al., 2018), and improving natural resource governance (Kshetri, 2017), like any powerful technology, the social and political costs and benefits of nascent blockchain applications remain ambiguous. 
This commentary explores how international development and climate change adaptation and mitigation credentials are being called upon to justify "crypto-colonialism" - neo-colonial processes (Stoneman and Suckling, 1987) whereby blockchain technology is enabling new forms of resource appropriation from the Global South. These appropriations include land, labor, data and other resources needed to facilitate economic growth elsewhere. The term Global South is used here to distinguish between spaces still suffering the scars of colonial expansionism, from those that have historically benefited from these processes (Kapoor, 2004). As with many past development agendas imposing structural economic reform, the contemporary crypto-colonial exercises discussed here are often framed as part of a "will to improve" (Li, 2007) - a quest for betterment enabling the powerful to use development and conservation discourses to legitimize particular claims at the expense of others (van Teijlingen and Hogenboom, 2016). Tsing (2005, p. 57) suggests that through such speculative enterprises, "profit must be imagined before it can be extracted; the possibility of economic performance must be conjured like a spirit to draw an audience of potential investors." The following section explores how investors are drawn to the sustainable development frontiers the code/spaces where crypto-colonial conjuring manifests. The paper then discusses three ways blockchain is implicated in colonial processes, exploring: (1) how the technology plays into ongoing narratives of "green grabbing," enabling the liquidation of resources for green investment, (2) how blockchain impacts persistent North-South trade and investment inequalities, and (3) how a new power asymmetry is enabled by the technology through data colonialism and surveillance capitalism. The paper concludes by discussing how more equitable outcomes might be realized.

\section{CLIMATE CRISES, CRYPTO-COLONIALISM AND THE GLOBAL SOUTH}

Despite being distributed, blockchain applications do not occupy an algorithmic place apart. They are always messily embedded in places (Zook and Blankenship, 2018; Lally et al., 2019). Governance frameworks of blockchain applications are heavily entangled with social-spatial relations in multiple ways (Dodd, 2018). The intertwining of code and materiality creates complex manifestations of "code/space" (Kitchin and Dodge, 2011). Within each code/space a unique assemblage of interests gain access to (or are excluded from) sites of crypto-economic production. The geographical character of the blockchain should be understood both in terms of the identification and spatial location of the infrastructure of, for example, private servers and data centers, where the distributed network is thought to materialize, as well as the "bundle of experimental algorithmic techniques acting upon the threshold of perceptibility itself" (Amoore, 2018, p. 12).

The costs and benefits of blockchain-based conservation, community development, and disaster relief, are rarely evenly distributed (Howson, 2020). Blockchain-based interventions in the Global South, though rooted in an obvious will to improve ( $\mathrm{Li}$, 2007) still call upon traditions of frontier investment - the belief that being bold and early in underexplored spaces enables the highest rewards (Li, 2014). As Bridge (2001) argues, frontiers are imagined (and constructed) as sites of bountiful emptiness. They are fecund spaces, empty but full. For their proponents, these sites are empty of other entrepreneurial ideas, histories and claims, but full of potential for new and improved use. As Tsing (2005, p. 28) explains, a frontier is "an edge of space and time: a zone of not yet - not yet mapped, not yet regulated. [...] The landscape itself appears inert: ready to be dismembered and packaged for export." Conjuring the plausibility of frontier resources for global cryptoeconomic exchange requires promoters to overlook the presence of people who remember long histories of recurrent dispossession and neo-colonial imposition.

Transnational market-based approaches to sustainable development, such as appropriations of land for community development, biodiversity conservation, and climate change adaptation and mitigation, are playing an increasingly central role in the global capitalist economy (Büscher and Fletcher, 2018). It should not be surprising when such market logic influences the development of "blockchain-for-good" initiatives. In doing so, blockchain projects enable new manifestations of the now well-established narrative of "disaster capitalism" (Klein, 2007). This thesis contends that neoliberal capitalism both precipitates disasters associated with climate change, while employing these same crises as an opportunity to facilitate the expansion of a neoliberal "green economy"1. Klein (2019) suggests that through the use of Blockchain technology the climate crises is enabling new forms of "crypto-colonialism." The term crypto-colonialism ${ }^{2}$ was coined before the invention of blockchain to refer to neo-colonial expansions toward host countries seeking to acquire greater political independence. This was at the expense of greater economic dependence upon the neo-colonial power. The term is used here in a slightly different way, to make sense of how blockchain technology enables new forms of "green grabbing" for global carbon markets, maintains North-South disparities using climate finance instruments, and enables data colonialism through the provision of humanitarian assistance for climate refugees. These projects are all legitimized under a banner of sustainable development in response to calls for urgent action on climate crises.

\section{GREEN GRABS FOR CRYPTOCARBON}

Blockchain technology is being leveraged to address the multiple technical faults of global carbon-offsetting mechanisms like Reducing Emissions from Deforestation and Forest Degradation $(\mathrm{REDD}+)$. The REDD + mechanism was established by the $\mathrm{UN}$ in 2007 to incentivize conservation and make tropical forests more valuable standing than cut down. However, since its inception many REDD + initiatives have become implicated

\footnotetext{
1 "Green economy" is flexibly defined by the UN Environment Programme as an economy that is low carbon, resource efficient and socially inclusive.

${ }^{2}$ For Herzfeld (2002), the term "crypto" was used to denote the clandestine nature of the colonial imposition.
} 
in "green grabbing" (Howson, 2018). Green grabbing can be understood as part of an on-going debate on neo-colonial "land grabbing" more generally (Pearce, 2013), involving the appropriation of land and resources with pro-environmental motives. This form of appropriation includes the transfer of land as property, use rights and control over natural resources that were once publicly or communally owned - or not the subject of ownership - from marginalized groups into the hands of the powerful (Fairhead et al., 2012). Green grabbing is not the same as a simple, agreed transfer of ownership or sale. It is a central characteristic to processes of accumulation and dispossession (Harvey, 2005). It is an emotive term because it is unjust. This form of grabbing often entails the expulsion of existing land claimants in order to release resources for private capital (Fairhead et al., 2012).

Blockchain projects, including Infinite Earth's Veridium Labs, a Hong Kong-based private company working in partnership with IBM and Stellar, are developing a platform to sell REDD + carbon off-sets as crypto-tokens. The value of Veridium's token, Verde, will be derived from the platform's ability to facilitate micro-payments of carbon credits produced mainly from Infinte Earth's Rimba Raya forest in Central Kalimantan (Howson, 2019). Despite the coordinated appearance of this vertically integrated consortium, the Rimba Raya project office in Indonesia remains uninformed of this approach to trading local people's forest resources. It is not clear how many options for future off-sets have been sold. There also remains no plan to offer financial compensation to local people. According to Enrici and Hubacek (2018), the Rimba Raya reserve is the only project of its kind in Indonesia to secure funding from global carbon markets. None of this income is shared with those paying the highest costs, such as those displaced by conservation efforts. Another cryptocarbon initiative, Impact Earth, have stated their intent toward incentivizing forest communities living in and around Zimbabwe's Kariba conservation area, via payments of their Ethereum-based Earth Token. Impact Earth state that, "People just like you can invest in a sustainable future and share in the success of this enormous opportunity" (in Howson et al., 2019, p. 6). However, no transfer of tokens could ever be made within the current global governance regime of cryptocommodity markets. Impact Earth specifically excludes investors from "high-risk" jurisdictions, as defined by the US Department of the Treasury's Financial Action Task Force and Office of Foreign Assets Control, which includes Zimbabwe (Lang, 2018b; Sullivan, 2018).

Athelia ${ }^{3}$, a private fund based in the tax haven of Luxembourg, is providing carbon credits associated with the Cordillera Azul National Park to its strategic Maltese partner, Poseidon, for use on their Ocean platform. Poseidon's platform allows consumers and retailers to track and offset their carbon footprints. Poseidon has

\footnotetext{
${ }^{3}$ The involvement of Althelia in the Cordillera Azul National Park conservation project also brings in Ecosphere + Limited, a company registered in the United Kingdom. Ecosphere + runs sales and marketing operations for Althelia's portfolio of environmental assets In November 2014, CIMA signed a Loan Agreement and Agency Agreement with Althelia Climate Fund. The contract with Althelia runs until at least 2021. Althelia has provided an $€ 8.55$ million loan - that finances three-quarters of the operations of the national park and its buffer zone (Lang, 2018a).
}

also partnered with Liverpool City Council and the London store of Ben \& Jerry's ice cream. The Rimba Raya reserve, as well as the Cordillera Azul National Park were established in 2007 and 2014 respectively. Off-setting one's emissions via the protected areas' blockchain platform enables the sale of carbon credits which have therefore already been produced. The profits from these sales repay the projects' private investors based overseas, rather than their local host communities. They do not directly incentivize any additional tree planting activities, or carbon "additionality." As Lang (2018a) suggests, with many market-based conservation projects, there is an unnecessary level of complexity in the funding arrangement, along with opportunities for only a small group of financiers, auditors, and consultants in the Global North to cash in along the way.

\section{BLOCKCHAIN FOR CLEAN DEVELOPMENT}

Environmental assets (or natural capital), are a monetized representation of the services natural systems provide for free. Off-sets and any crypto-tokens associated with them, derive their value from the health of conserved biophysical systems. Due to the dynamic nature of atmospheric $\mathrm{CO}_{2}$, in the context of the global climate system, it does not matter where in the world emissions are avoided. Global markets for saved carbon can be used to ensure net emissions are reduced at the cheapest price. For this reason, most of the world's carbon-offset initiatives are located in the Global South, where land, labor and other necessary inputs can be sourced cost-effectively for maximum potential profit (Howson, 2018). The problem with producing environmental derivatives in this way is that an abstract "nature," people and their livelihoods are arranged as underlying assets for the "real" source of value in the neoliberal green economy (Büscher, 2010). For-profit companies such as Adaptation Ledger, Climate Trade and Climate Futures have launched blockchain platforms for carbon off-setting, green financing and sustainable investments. The 1Planet blockchain platform developed by Climate Futures enables purchases of environmental assets from energy efficiency initiatives in Africa, Latin America and India. Individuals and companies can purchase carbon credits as blockchain tokens to reduce their net emissions by supporting, for example, the installation and distribution of fuelefficient cooking stoves in Zambia. The value of these credits are derived from the assumption that concrete stoves reduce wood-use for cooking compared to traditional open fires. The projects' carbon offsets are certified through the UN Clean Development Mechanism and are marketed toward international airlines specifically, to help them meet climate change obligations under the UN Carbon Offsetting and Reduction Scheme for International Aviation (CORSIA). The implication here is that forest communities in the Global South, collecting dry wood for cooking and often living with a near neutral carbon footprint (Gazull and Gautier, 2014), are framed as more responsible for climate change, compared to frequent flyers and large multinational corporations in the Global North.

The Green Assets Wallet has been developed to help scale the green debt market, primarily in Africa. The blockchain 
platform functions as a tool for green bond validation and impact reporting and has been developed by a consortium including the German International Development Agency (GIZ) and the German Federal Ministry for Economic Cooperation and Development (BMZ) (Green Assets Wallet, 2019). Green bonds operate just like conventional debt instruments, with similar calculations of risk and credit rating. However, dividends are actioned against contracted sustainability outcomes, usually including a calculation of achieved emissions reductions from the associated investment. As a debt instrument, Green bonds in Africa are generally high-risk due to the poor credit ratings of recipient countries. Using blockchain to bring trust to these transactions risks maintaining pre-existing North-South trade and investment flows and neo-colonial geographies of inequality that render much of the global south increasingly marginalized. Scaling up green debt markets in Africa restricts the organic growth of green enterprises as they risk their returns disappearing to international investors, whose income may be guaranteed by public sector entities (Bracking, 2019). The most environmentally-effective solution for companies and individuals with high carbon footprints, whose sites of production are located in the Global North, is obvious - prevent excessive pollution at source. The most cost-effective solution is usually more creative, requiring innovative financial instruments and accounting methodologies, and the ongoing externalization of environmental costs toward the Global South.

In opposition to traditional North-South investment flows, rather than monetizing removals only from the Global South, the Nori Marketplace uses blockchain technology to incentivize land-owners in the Global North. Farmers in the US can receive rewards for adopting regenerative practices that mitigate climate change and improve the carbon content of soils. Individuals and businesses can purchase NORI tokens that are tradable via cryptocurrency exchanges (Siegel, 2019). Tokens represent verified Nori Removal Tonnes (NRTs), which each represent one tonne of $\mathrm{CO}_{2}$ removed from the atmosphere for a minimum of 10 years. Retirement of the NRTs is immediate and generates a certificate that is permanently recorded on the Ethereum blockchain. The platform's developers suggest that Nori enables a win-win outcome for consumers and the climate (Gambill, 2019). However, as with any carbon off-set, these assets are a fetishized abstraction of an unfathomably complex biophysical system (Howson et al., 2019). Blockchain tokens are not capable of representing much more than a rough estimate concerning temporarily removed carbon over time. Knowing what will happen from one year to the next, or what might have happened in the absence of a farmer's intervention is impossible. To add to the uncertainty, Nori's verification methodology also requires the input of trusted third party intermediaries. Which begs the question, why use a blockchain at all?

\section{DATA COLONIALISM AND CLIMATE REFUGEES}

Appropriations of things, including data, are legitimized by a necessity for urgent climate action. Data colonialism for environmental ends combine the extractive practices of historical colonialism with the abstract quantification methods of computing that works at every point in space where people and/or things are attached to everyday communication infrastructures (Couldry and Mejias, 2018). This mode of colonialism could also be thought of as surveillance capitalism, whereby the territory claimed by climate-minded blockchain projects includes land, labor and other resources, but also private human experience to be used as "behavioral data" for "prediction products" (Zuboff, 2019). Unlike traditional forms of colonialism, data colonialism involves not one center of colonial power (the West), but multiple. These centers include, for example, Facebook, Palantir, Accenture and Microsoft, and according to Kinstler (2019) these players are seeing extractive opportunities from human migration caused by climate change. In 2017, 24 million people were displaced because of extreme climatic events (Podesta, 2018) and by 2050, over 143 million people across the Global South are predicted to become climate refugees (Rigaud et al., 2018). The acceleration of people on-the-move provides challenges for development agencies committed to achieving various Sustainable Development Goals (SDGs) efficiently. These include SDG 16.9 (provide legal identity for all, including birth registration, by 2030), and SDG 17.19 (provide statistical capacity-building to increase the proportion of countries that have achieved 100 per cent birth registration and 80 per cent death registration. Every major aid-granting agency is either incubating, researching, or piloting a digital identity program for those displaced (Kinstler, 2019).

To enable the distribution of cash-for-food aid, the World Food Programme's (WFP) Building Blocks initiative is collecting personal data, including biometrics, from over 500,000 Syrian refugees in Jordan (Rugeviciute and Mehrpouya, 2019). Personal data, entitlements and transaction logs are stored on the Ethereum blockchain providing a virtual bank account and ID for each refugee. While the Building Blocks platform is a demonstrable success, the agency should be concerned that conducting iris scans on refugees in shops robs them of dignity. Sensitive, personally identifiable information for some of the most vulnerable people in the world is also being generated and made accessible across agencies, inevitably introducing greater risk of data breaches. Some for-profit start-ups have also developed blockchain tools to manage sensitive information. PassBase is a self-sovereign ID platform that uses governmentissued documents, linked social media accounts, and biometric signatures. Where these blockchain platforms are deployed, refugees and other vulnerable people, might find themselves forced to give up personal (including biometric) information about themselves, stored for as long as there is a functioning internet on an immutable archive, in return for temporary support with basic necessities. This data could also be used in the future to make decisions about individuals with far-reaching consequences. Some may suffer punitive restrictions based on decisions made using biased algorithms calculating, for example, risk of absconding or working without a permit. Some may struggle to access credit or insurance on the basis of patterns in historical datasets. Wrongful convictions, incomplete medical 
histories, or errors concerning ones affiliations are immutable on a blockchain.

Owning ones ID as a citizen of a specific state might prove unproblematic in many instances. However, groups such as the Rohingya are continually displaced by climatic events and their citizenship is often contested between the state and the individual. Bank accounts, passports, access to credit or insurance are restricted even where clear jus soli (citizenship rights by birth) exist. Rohingya refugees are often considered legally "stateless" and denied the necessary proofs to enable a digital ID granting them legal attachment to their birthplace (Bremner, 2020). The blockchain development start-up, Rohingya Project, understand that the central problem is not identity per se, as being officially recognized as Rohingya is rarely useful. The Rohingya Project aims to create a self-sovereign ID platform that does not rely on any state entity or other third-party intermediary to issue supporting documents. Users of the platform in Malaysia will be able to access credit and other services via a crypto-wallet to encourage entrepreneurship and financial sustainability within the Rohingya community (Rohingya Project, 2020). Data shared by some of the most persecuted on a blockchain, highlights the obvious need for a more robust regulatory framework to effectively mitigate the risks associated with data protection, privacy and human rights.

\section{CONCLUSION}

Blockchain is enabling new opportunities for speculative investment through climate crises globally. This commentary has explored how international development, disaster relief, and climate change mitigation credentials are being called upon to legitimize crypto-colonialism - the extraction of economic benefits from those suffering the scars of empire in the Global South. Climate-smart blockchain platforms enable ongoing narratives of "green grabbing," perpetuating

\section{REFERENCES}

Amoore, L. (2018). Cloud geographies: computing, data, sovereignty. Prog. Hum. Geogr. 42, 4-24.

Bálint, M., Domisch, S., Engelhardt, C. H. M., Haase, P., Lehrian, S., Sauer, J., et al. (2011). Cryptic biodiversity loss linked to global climate change. Nat. Clim. Change 1, 313-318.

Bracking, S. (2019). Financialisation, climate finance, and the calculative challenges of managing environmental change. Antipode 51, 709-729.

Bremner, L. (2020). Sedimentary logics and the Rohingya refugee camps in Bangladesh. Polit. Geogr. 77;102109.

Bridge, G. (2001). Resource triumphalism: post-industrial narratives of primary commodity production. Environ. Plann. A 33, 2149-2173.

Büscher, B. (2010). Derivative nature: interrogating the value of conservation in 'Boundless Southern Africa'. Third World Quart. 31, 259-276.

Büscher, B., and Fletcher, R. (2018). Under pressure: conceptualising political ecologies of green wars. Conserv. Soc. 6, 105-113.

Büscher, B., and Fletcher, R. (2020). The Conversation Revolution: Radical Ideas for Saving Nature Beyond the Anthropocene. London: Verso.

Couldry, N., and Mejias, U. (2018). Data colonialism: rethinking big data's relation to the contemporary subject. Telev. New Media 20, 336-349.
North-South trade and investment inequalities, whilst allowing new power asymmetry through data colonialism and surveillance capitalism. Despite blockchain's ongoing disruption of most economic, political and social institutions, the main challenge for the technology is to protect itself from the inherent tendencies of modern capitalist society and the associated concentrations of wealth and power in the Global North (De Filippi and Loveluck, 2016). There continues to be a lot of hype surrounding blockchain applications, fanciful use-cases and sinks for speculative investment. Despite there still being few successful examples, there is a clear need for more situated critical analysis of active case-studies. Only by doing casestudy analysis can critical scholars reveal the inequitable terrain of project-benefit distributions to expose the likely winners and losers. The most effective means of engaging exploitative blockchain platforms is by supporting and enacting alternate techno-economic strategies, such as platform cooperatives, within and outside of blockchain. If any project, blockchain or otherwise, claims to be emancipatory, the foremost step is to abandon the claims of a technology as a starting point, and instead give autonomy and agency to local communities to design and manage their own future, rather than having outside interests, or technologies themselves, determine a future for them (Crandall, 2019). The crypto-colonial endeavors, explored throughout this commentary, remain ultimately about advancing capitalist forms of governance. Until the focus shifts toward achieving more equitable outcomes, not only will blockchain solutions lead to an oversimplification of socioecological complexity, but will further embed colonial responses to climate crises.

\section{AUTHOR CONTRIBUTIONS}

The author confirms being the sole contributor of this work and has approved it for publication.

Crandall, J. (2019). Blockchains and the "Chains of Empire": contextualizing blockchain, cryptocurrency, and neoliberalism in puerto rico. Des. Cult. 11, 279-300.

De Filippi, P., and Loveluck, B. (2016). The invisible politics of Bitcoin: governance crisis of a decentralised infrastructure. Internet Policy Rev. 5, 1-28.

Dodd, N. (2018). The social life of bitcoin. Theory Cult. Soc. 35, 35-56.

Enrici, A. M., and Hubacek, K. (2018). Challenges for REDD+ in Indonesia: a case study of three project sites. Ecol. Soc. 23:7.

Fairhead, J., Leach, M., and Scoones, I. (2012). Green grabbing: a new appropriation ofcnature? J. Peasant Stud. 39, 237-261.

Gambill, P. (2019). Stop Worrying About Flight Shame, and Just Remove the CO2 You Emit. [online] Medium. Available online at: https://medium.com/nori-carbon-removal/stop-worrying-about-flightshame-and-just-remove-the-co2-you-emit-468a2ae90828 (accessed April 7, 2020).

Gazull, L., and Gautier, D. (2014). Woodfuel in a global change context. Wiley Interdiscip. Rev. Energy Environ. 4, 156-170.

Green Assets Wallet (2019). Africa Guide for Investors. [online] Green Assets Wallet. Available online at: https://greenassetswallet.org/africa-guide-investors (accessed April 7, 2020).

Harvey, D. (2005). A Brief History of Neoliberalism. Oxford: Oxford University Press. 
Herzfeld, M. (2002). The absent presence: discourses of crypto-colonialism. S. Atlant. Q. 101, 899-926.

Howson, P. (2018). Slippery violence in the REDD+ forests of central Kalimantan, Indonesia. Conserv. Soc. 16, 136-146.

Howson, P. (2019). Tackling climate change with blockchain. Nat. Clim. Change 9, 644-645.

Howson, P. (2020). Building trust and equity in marine conservation and fisheries supply chain management with blockchain. Mar. Policy 115:103873.

Howson, P., Oakes, S., Baynham-Herd, Z., and Swords, J. (2019). Cryptocarbon: the promises and pitfalls of forest protection on a blockchain. Geoforum 100, 1-9.

Kapoor, I. (2004). Hyper-self-reflexive development? Spivak on representing the third world "Other". Third World Q. 4, 627-647.

Kinstler, L. (2019). Big Tech Firms are Racing to Track Climate Refugees. [online] MIT Technology Review. Available online at: https://www.technologyreview. $\mathrm{com} / \mathrm{s} / 613531 /$ big-tech-firms-are-racing-to-track-climate-refugees/ (accessed April 7, 2020).

Kitchin, R., and Dodge, M. (2011). Code/Space: Software and Everyday Life. Cambridge, MA: MIT Press.

Klein, N. (2007). The Shock Doctrine. London: Penguin.

Klein, N. (2019). Puerto Ricans and Ultrarich "Puertopians" Are Locked in a Pitched Struggle Over How to Remake the Island. [online] The Intercept. Available online at: https://theintercept.com/2018/03/20/puerto-rico-hurricane-mariarecovery/ (accessed June 19, 2019).

Kshetri, N. (2017). Will blockchain emerge as a tool to break the poverty chain in the Global South? Third World Q. 38, 1710-1732.

Lally, N., Kay, K., and Thatcher, J. (2019). 'Computational parasites and hydropower: a political ecology of bitcoin mining on the columbia river', environment and planning E. Nat. Space 8, 1-21.

Lang, C. (2018a). Can buying Ben \& Jerry's ice cream save the Cordillera Azul National Park in Peru? REDD-Monitor. Available online at: https://reddmonitor.org/2018/11/09/can-buying-ben-jerrys-ice-cream-save-the-cordilleraazul-national-park-in-peru-featuring-ecosphere-althelia-the-poseidon-found ation-redd-blockchain-and-the-government-of-malta/ (accessed June 19, 2019).

Lang, C. (2018b). The Kariba REDD project in Zimbabwe: From carbon credits to EARTH Tokens. [online] REDD-monitor.org. Available online at: http://www.redd-monitor.org/2018/02/08/the-kariba-redd-project-inzimbabwe-from-carbon-credits-to-earthtokens/ (accessed August 3, 2018).

Li, T. M. (2007). The Will to Improve: Governmentality, Development, and The Practice of Politics. Durham: Duke University Press.

Li, T. (2014). Land's End. Durham: Duke University Press.

Marke, A. (2018). Transforming Climate Finance and Green Investment with Blockchains. Cambridge, MA: Academic Press.

Pearce, F. (2013). Land Grabbers: The Fight over Who Owns the Earth. Boston, MA: Beacon.
Podesta, J. (2018). The Climate Crisis, Migration, And Refugees. Available online at: https://www.brookings.edu/research/the-climate-crisis-migrationand-refugees (accessed April 7, 2020)

Rigaud, K., de Sherbinin, A., Jones, B., Bergmann, J., Clement, V., Ober, K., et al. (2018). Groundswell. Available online at: https://openknowledge.worldbank. org/handle/10986/29461 (accessed April 7, 2020).

Rohingya Project (2020). Rohingya Project. Available online at: https: //rohingyaproject.com/about/ (accessed April 7, 2020).

Rugeviciute, A., and Mehrpouya, A. (2019). Blockchain, a panacea for development accountability? A study of the barriers and enablers for blockchain's adoption by development aid organizations. Front. Blockchain 2:15. doi: 10.3389/fbloc.2019. 00015

Siegel, R. (2019). Can This Company Build A Better Carbon Offset? [online] Grist. Available online at: https://grist.org/article/can-this-company-build-a-bettercarbon-offset/ (accessed April 7, 2020).

Stoneman, C., and Suckling, J. (1987). From apartheid to neocolonialism? Third World Q. 9, 515-544.

Sullivan, S. (2018). Nature 3.0 - Will Blockchain Technology and Cryptocurrencies Save the Planet?. Available online at: https://entitleblog.org/2018/02/01 /nature-3-0-willblockchain-technology-and-cryptocurrencies-save-the-planet/ (accessed November 8, 2018).

Thomason, J., Ahmad, M., Bronder, P., Hoyt, E., Pocock, S., Bouteloupe, J., et al. (2018). Blockchain-powering and empowering the poor in developing countries. Transform. Clim. Financ. Green Invest. Blockchains 137-152. doi: 10.1016/B978-0-12-814447-3.00010-0

Tsing, A. L. (2005). Friction: An Ethnography of Global Connection. Princeton, NJ: Princeton University Press.

van Teijlingen, K., and Hogenboom, B. (2016). Debating alternative development at the mining frontier: buen vivir and the conflict around el mirador mine in ecuador. J. Dev. Soc. 32, 382-420.

Zook, M., and Blankenship, J. (2018). New spaces of disruption? The failures of Bitcoin and the rhetorical power of algorithmic governance. Geoforum 96, 248-255.

Zuboff, S. (2019). The Age of Surveillance Capitalism. London: Profile Books.

Conflict of Interest: The author declares that the research was conducted in the absence of any commercial or financial relationships that could be construed as a potential conflict of interest.

Copyright $(0) 2020$ Howson. This is an open-access article distributed under the terms of the Creative Commons Attribution License (CC BY). The use, distribution or reproduction in other forums is permitted, provided the original author(s) and the copyright owner(s) are credited and that the original publication in this journal is cited, in accordance with accepted academic practice. No use, distribution or reproduction is permitted which does not comply with these terms. 